\title{
Effect of broodstock holding environment on egg quality in farmed brown trout (Salmo trutta)
}

\author{
D.S. Murray ${ }^{1,4}$, C.E. Adams ${ }^{2}$, K. McDade ${ }^{1}$, S.E. Solomon ${ }^{3}$, M.M. Bain ${ }^{1}$ \\ ${ }^{1}$ Institute of Biodiversity, Animal Health and Comparative Medicine, University of Glasgow, Glasgow, G61 1QH, Scotland, UK. \\ ${ }^{2}$ IBAHCM. Scottish Centre for Ecology and the Natural Environment (SCENE), University of Glasgow, Loch Lomond, \\ Rowardennan, G63 0AW, Scotland, UK. \\ ${ }^{3}$ Vigonac, 24310, Brantome, France.
}

\begin{abstract}
Brown trout (Salmo trutta) broodstock from a single population were separated prior to spawning and exposed to two different holding environments: a 'raceway system' and a 'tank system'. Eggs were stripped from females and 13 measures of egg quality were collected, analysed individually, combined by principle components analysis into an integrated egg quality score which was validated against egg survival. The multivariate egg quality score (PC1) differed for fish held in the tank and raceway systems. Egg survival, chorion breaking strength and chorion Se concentrations were higher in eggs produced by broodstock held in the tank system compared to those in the raceway system. In contrast, chorion concentrations of $\mathrm{P}$ and $\mathrm{K}$ were higher in eggs from fish held in the raceway system. The results suggest that brown trout broodstock reared in tank systems produced higher quality eggs compared to trout reared in raceways. Finally, this study also indicates that multivariate statistical analysis can be used to determine egg quality from multiple egg parameters.
\end{abstract}

Keywords: chorion, egg, environment, multivariate, raceway, tank.

\section{Introduction}

The quality of eggs produced by farmed fish continues to be a significant factor limiting the expansion of the aquaculture industry (Kjorsvik et al., 1990). For example, species such as Atlantic halibut (Hippoglossus hippoglossus) have considerable potential for commercial production; however, hatching rates of less than $1 \%$ continue to obstruct the growth of the industry (Norberg et al., 1991; Mommens et al., 2011). Even in families such as the Salmonidae, where there has been considerable work on culture and incubation systems, egg mortality rates of up to $50 \%$ still occur (Bromage et al., 1992; Brooks et al., 1997; Bobe and Labbe, 2010).

Within aquaculture, egg quality is defined by the survival rate or the number of eggs which fertilise, reach the eyed stage of development, and hatch successfully (Brooks et al., 1997; Bobe and Labbe, 2010). However, while survival rates provide information on hatching success they fail to describe the intrinsic properties of the egg, which have influenced hatching success. Previous studies have suggested a number of characteristics may be used to determine egg quality; these include egg size, morphology, distribution of yolk components within the egg and the biochemistry of the ovarian fluid (Kjorsvik et al., 1990; Brooks et al., 1997; Bobe and Labbe, 2010).

Studies have also shown that there are a number of factors which may affect egg quality during various stages of its development (Bobe and Labbe, 2010). For example, the quality of an egg may be influenced by the intrinsic properties of the brood fish prior to, and during, ovulation (Brooks et al., 1997). Female rainbow trout (Oncorhynchus mykiss) with elevated stress levels (as defined by increased blood cortisol concentrations) 9 months prior to spawning, produced eggs with significantly lower survival rates compared to fish with lower stress levels (Campbell et al., 1992). A diverse selection of dietary components, including lipids, fatty acids, protein and trace minerals have also been shown to influence egg quality (Brooks et al., 1997; Izquiredo et al., 2001). For example, Washburn et al. (1990) found that rainbow trout fed a diet deficient in carbohydrates, produced eggs with a lower survival rate compared to con-specifics fed a high carbohydrate diet.

Once the egg is released for fertilisation, extrinsic factors such as the physio-chemical conditions of the water (temperature, salinity, and $\mathrm{pH}$ ) may also affect egg quality (Brooks et al., 1997). Water temperature during incubation is particularly important as it may affect metabolism, development, and subsequently survival of the embryo (Kinne and Kinne, 1961). In salmonids, extremely high or low temperatures can significantly impact egg mortality at early stages of development (Brooks et al., 1997).

According to Ebeling and Timmons (2012) an adequate tank design should provide uniformity of rearing conditions, fast elimination of waste products (non-ingested feed and faeces) and uniform distribution of fish throughout the enclosure. Two systems, which meet these requirements and are currently used for salmonid farming are tanks and raceways (Bostock et al., 2010). Both systems provide a greater level of control over extrinsic factors compared to equivalent systems, such as earth ponds and sea cages (Pillay, 1993). Water supply and drainage in tank systems is commonly organised in such a way as to create a vortex, which sweeps most of the detritus and other waste material out of the system (Pillay, 1993). In comparison, 
raceways are designed to provide a flow through system, which enables the rearing of much denser populations but also relies on an abundant flow of well oxygenated water (Pillay, 1993; Bostock et al., 2010). Tanks and raceways are often constructed from the same materials (i.e. concrete, marine plywood, metal, or fibreglass) but their intrinsic properties, such as water inlets and drainage pipes can create substantial hydrological differences between each system (Pillay 1993).

While many previous investigations have identified how intrinsic factors affect egg quality in preovulating broodstock, little is known about how extrinsic factors, such as the holding environment affect broodstock in a way that impacts upon egg quality (Kjorsvik et al., 1990; Brooks et al., 1997; Izquierdo et al., 2001). Therefore, in the current study, we address this question directly by examining extrinsic environmental effects on egg quality mediated through the female by rearing two groups of brown trout in two different rearing environments. In addition to utilising standard methods to define egg quality we also examined other novel measures of egg quality and how alternative data analysis can be used to test for differences in egg quality.

\section{Materials and Methods}

\section{Samples and location}

Forty female brown trout (Salmo trutta; age: $2+)$ from the Ae Fishery, Dumfries, were used in this study. All fish were from the same strain. Trout were transported to aquarium facilities at the Scottish Centre of Ecology and the Natural Environment (S.C.E.N.E.) University of Glasgow and held at these facilities from June 2008 until February 2009.

\section{Broodstock holding environment: tank system}

Broodstock were held in an $800 \mathrm{~L}$ round, polyethylene tank with a continuous supply of water (ca. $25 \mathrm{~L} \mathrm{~min}^{-1}$ ), provided by three inlet pipes equidistant around the circumference of the tank. Waste water was drained using a central stand-pipe covered by a $5 \mathrm{~mm}$ mesh screen. Fish were exposed to ambient water temperature and natural photoperiod. Industrial food pellets (EWOS Ltd) were dispensed daily into the tank by a clockwork belt feeder (Dryden Aqua Ltd) over a $24 \mathrm{~h}$ feeding period. The daily feed ration exceeded the recommended feeding rate for salmonids for the prevailing water temperature. Mean water temperature for the duration of the experiment was $11^{\circ} \mathrm{C}$.

\section{Broodstock holding environment: raceway system}

Trout were held in a $1000 \mathrm{~L}$ raceway and exposed to ambient water temperature and natural photoperiod. Water entered the raceway from a pipe at one end of the raceway (ca. $25 \mathrm{~L} \mathrm{~min}^{-1}$ ), while waste water was drained by a standpipe screened by $5 \mathrm{~mm}$ mesh located at the other end of the raceway. Industrial food pellets (EWOS Ltd) were deposited into the tank by a clockwork belt feeder (Dryden Aqua Ltd) set to a $24 \mathrm{~h}$ continual feeding regime. The feed ration exceeded the recommended weight for salmonids. Mean water temperature for the duration of the experiment was $11^{\circ} \mathrm{C}$.

\section{Assessing reproductive status of broodstock}

Reproductive maturation in individual trout was assessed, every second day, between October 2008 and February 2009, by anaesthetising fish in a benzocaine solution (Sigma Life Sciences) and checking visually for signs of abdominal distension and egg release. Broodstock that were not ovulating were placed in a $150 \mathrm{~L}$ recovery tank, before being returned to the holding tank. Ovulating fish were euthanized by exposure to a lethal dose of anaesthetic, followed by a sharp blow to the head (The Humane Killing of Animals (Schedule 1) Act, 1986; Humane, 1997). Fish were blotted dry and their eggs were stripped into clean dry plastic tubs by abdominal manipulation.

\section{Egg survival}

Approximately 500 eggs (estimated by weight) collected from each female were sub-divided into two replicates, and fertilised by a single male. Eggs were then water hardened and placed into individual custombuilt incubation trays. Water hardening, in this context, occurs when eggs come into contact with water. The difference in osmolarity between the inside of the egg and the water causes an influx of water into the perivitelline space of the egg. This causes the eggs to swell in size and a cross-linking of chorion proteins (Rudy and Potts, 1969; Oppen-Berntsen et al., 1990). Incubation trays were constructed from plastic mesh $(5$ $\mathrm{mm}$ mesh diameter) wrapped round a solid square Perspex base and $\operatorname{rim}(10 \times 10 \times 15 \mathrm{~cm})$. These trays were placed in a $200 \mathrm{~L}$ flow-through tank $\left(5 \mathrm{~L} \mathrm{~min}^{-1}\right)$ containing two water filters (Fluval A460). The eggs in individual trays were checked every alternate day for mortalities. Dead eggs were identified by their white/opaque appearance, recorded and removed from the incubation system. The experiment was terminated when all eggs reached the eyed stage of development. Water temperature during egg incubation ranged between 5 and $14^{\circ} \mathrm{C}\left(\right.$ mean $\left.=8^{\circ} \mathrm{C}\right)$

\section{Chorion breaking strength}

Ten unfertilised, non-water hardened and ten unfertilised, water hardened eggs from each female were selected to measure chorion strength. The breaking strength of each individual chorion was tested using a Lloyd LRX compression test instrument (Ametek Inc). With the following settings, $1 \mathrm{~mm}$ diameter blunt ended probe, $5 \mathrm{~mm} \mathrm{~min}^{-1}$ probe speed with a $5 \mathrm{~N}$ load cell.

\section{Chorion element concentrations}

Four unfertilised, non-water hardened eggs from each female were gently punctured with a sterilised needle. The yolk was extruded by gentle 
manipulation of the chorion. Each chorion was then placed in individually marked well-plates and dried at $37^{\circ} \mathrm{C}$ for $24 \mathrm{~h}$. These were then mounted onto aluminium stubs using double sided sticky carbon tabs. Analysis of elemental concentrations was then carried out by energy-dispersive x-ray spectroscopy (E.D.X.), using a Philips XL30 ESEM equipped with a Phoenix energy dispersive $\mathrm{x}$-ray detector (operating voltage $=$ $20 \mathrm{kv}$, working distance $=10 \mathrm{~mm}$ ). Carbon $(\mathrm{C})$, oxygen $(\mathrm{O})$, sodium $(\mathrm{Na})$, magnesium $(\mathrm{Mg})$, phosphorus $(\mathrm{P})$, sulphur $(\mathrm{S})$, chlorine $(\mathrm{Cl})$, potassium $(\mathrm{K})$, calcium $(\mathrm{Ca})$, and selenium $(\mathrm{Se})$ were all consistently detected during analysis. The percentage concentration of each of these elements was derived for the chorion of each individual egg.

\section{Data analysis}

Principle components analysis (PCA) was used to reduce the number of egg quality variables into a single multivariate egg quality score (Turnbull et al., 2005; Adams et al., 2007). The egg quality variables were combined by means of a multivariate analysis. Principle components analysis (PCA) was conducted on individual egg variables and the components (with significant positive and negative loadings for all egg variables measured, Table 1) were used as a score of general egg quality. This principle component scores incorporated physical (chorion breaking strength) and biochemical (elemental concentrations) measures of egg quality. Therefore, factor scores produced by PCA provided a single integrated egg quality value, which increased with improving quality. To test the validity of using PCA scores to define egg quality, PCA scores were regressed on egg survival for each female. Oneway analysis of variance (ANOVA) was then used to examine the effects of broodstock holding environmental on this multivariate egg quality score. The effect of broodstock holding environment on individual egg quality variables was examined using ANOVA. All data presented as percentages were arcsine transformed prior to analysis. The Minitab ${ }^{\circledR} 16$ statistical software package was used for data analysis.

The logistical constraints and financial demands of multiple holding unit replicates, particularly at the commercial site made holding unit replication in this study impossible. This is a common problem for studies involving commercial partners that has been recognised in many other studies. Oksanen (2001) argued that when the cost of replication is very high, experiments involving un-replicated treatments may be the only option, cautious use of inferential statistic may be acceptable. In the context of the design of this current study one assumption made is that the response of individual females is independent of others in the tank. Given that we are examining the physiological and bioallocation responses of individual females, this is both a logical and reasonable assumption.

Table 1. PCA coefficients applied to each variable measured and the total variation explained (\%).

\begin{tabular}{|c|c|c|c|c|}
\hline Variable & PC1 & PC2 & PC3 & PC4 \\
\hline Non-water hardened chorion breaking strength & -0.38 & 0.12 & 0.17 & -0.32 \\
\hline Water hardened chorion breaking strength & -0.36 & 0.02 & 0.28 & -0.31 \\
\hline Se chorion conc & -0.21 & 0.15 & 0.54 & 0.30 \\
\hline C chorion conc & 0.24 & -0.46 & 0.17 & 0.06 \\
\hline O chorion conc & -0.35 & 0.04 & -0.34 & -0.02 \\
\hline $\mathrm{Na}$ chorion conc & -0.06 & -0.03 & 0.61 & 0.24 \\
\hline $\mathrm{Mg}$ chorion conc & 0.09 & 0.12 & -0.15 & 0.68 \\
\hline $\mathrm{P}$ chorion conc & 0.42 & -0.02 & 0.09 & -0.26 \\
\hline S chorion conc & 0.33 & 0.25 & 0.15 & -0.32 \\
\hline $\mathrm{Cl}$ chorion conc & 0.07 & 0.59 & 0.07 & -0.03 \\
\hline $\mathrm{K}$ chorion conc & 0.44 & 0.03 & 0.12 & -0.10 \\
\hline Ca chorion conc & 0.10 & 0.58 & -0.10 & 0.07 \\
\hline Variance explained (\%) & 31.8 & 22.3 & 14.6 & 12.0 \\
\hline
\end{tabular}

\section{Results}

\section{Multivariate egg quality score and egg survival}

The first principle component (PC 1) of the PCA analysis of 12 putative egg quality variables accounted for $37.8 \%$ of the total variance of the PCA analysis and showed high negative coefficients for nonhardened and hardened chorion breaking strengths, $\mathrm{O}$ and Se chorion concentrations, opposed with high positive coefficients for $\mathrm{P}, \mathrm{S}$ and $\mathrm{K}$ chorion concentrations (Table 1). The second, third and fourth components (PC2, PC3 and PC4 respectively) also accounted for a considerable amount of variation (22.3, 14.6, and $12.0 \%$, respectively). PC2 showed a high negative coefficient for $\mathrm{C}$ chorion concentrations and high positive coefficients for $\mathrm{Cl}$ and $\mathrm{Ca}$ chorion concentrations, while PC3 showed a high negative coefficient for $\mathrm{O}$ chorion concentrations and high positive coefficients for $\mathrm{Se}$ and $\mathrm{Na}$ chorion concentrations (Table 1).

PC1 scores were negatively correlated with egg survival across females $\left(\mathrm{F}_{[1,15]}=9.97 ; \mathrm{R}^{2}=0.399 ; \mathrm{P}=\right.$ 0.007), while PC3 scores were positively correlated to egg survival across females $\left(\mathrm{F}_{[1,15]}=4.88 ; \mathrm{R}^{2}=0.399 ; \mathrm{P}=\right.$ $0.043)$. There was no significant correlation for $\mathrm{PC} 2$ $\left(\mathrm{F}_{[1,15]}=0.27 ; \mathrm{R}^{2}=0.018 ; \mathrm{P}=0.609\right)$ or $\mathrm{PC} 4\left(\mathrm{~F}_{[1,15]}=2.67\right.$; $\left.\mathrm{R}^{2}=0.151 ; \mathrm{P}=0.123\right)$. Therefore, $\mathrm{PC} 1$ provides a useful index of increasingly poor egg quality (higher PC1 score; lower egg quality) and PC3 of increasing higher egg 
quality (higher PC3 score; higher egg quality). PC2 and PC4 scores do not appear to reflect elements of egg quality that affect survival and thus were not considered further.

Multivariate egg quality index (PC1 and PC3) and broodstock holding environment

PC1 egg quality scores were significantly lower in eggs from fish reared in the tank system compared to the raceway system $\left(\mathrm{F}_{[1,15]}=18.95 ; \mathrm{R}^{2}=0.558 ; \mathrm{P}=\right.$ 0.001 ; Fig. 1), indicating that eggs from broodstock held in the tank had higher chorion breaking strength (water hardened and non-water hardened) and chorion $\mathrm{O}$ concentrations and had lower $\mathrm{P}, \mathrm{S}$ and $\mathrm{K}$ chorion concentrations. There was no difference in PC3 egg quality scores of eggs between holding sites $\left(\mathrm{F}_{[1,15]}=\right.$ 3.06; $\mathrm{R}^{2}=0.169 ; \mathrm{P}=0.101$; Fig. 1).

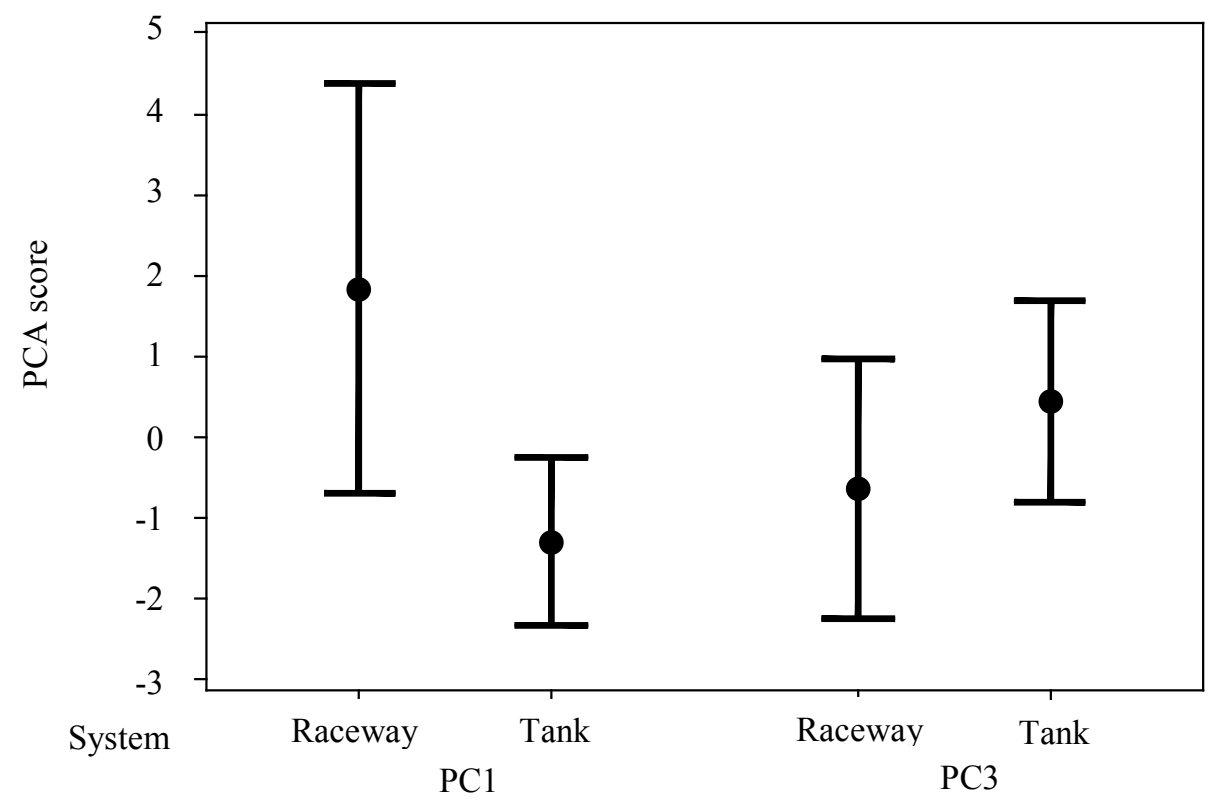

Figure 1. Differences in PC egg quality scores between Raceway and Tank systems. PC1, raceway $(1.85 \pm 1.91)$ and tank systems $(-1.29 \pm 1.07)$, and PC3, raceway $(-0.63 \pm 1.21)$ and tank systems $(0.44 \pm 1.27)$. $(\mathrm{mn} \pm \mathrm{std}$ dev).

The effect of broodstock holding environment on individual measures of egg quality

Egg survival was significantly greater in eggs produced by females reared in the tank system compared to those held in the raceway $\left(\mathrm{F}_{[1,15]}=31.8\right.$; $\mathrm{R}^{2}=0.66 ; \mathrm{P}<0.001$; Table 2). Univariate analysis of individual measures of putative egg quality showed that eggs produced by female broodstock held in the tank had a higher chorion breaking strength for both non-water hardened and water hardened eggs compared to those held in the raceway (non-water hardened; $\mathrm{F}_{[1,15]}=201.3$; $\mathrm{R}^{2}=0.93 ; \mathrm{P}<0.001$, water hardened; $\mathrm{F}_{[1,15]}=125.0 ; \mathrm{R}^{2}$ $=0.89 ; \mathrm{P}<0.001 ;$ Table 2$)$. The chorion of the eggs produced by female broodstock held in the tank system had a higher percentage concentration of $\mathrm{Se}\left(\mathrm{F}_{[1,15]}=5.1\right.$; $\mathrm{R}^{2}=0.20 ; \mathrm{P}=0.040$; Table 2), whilst those from female broodstock held in the raceway system had significantly higher levels of both $\mathrm{P}$ and $\mathrm{K}\left(\mathrm{P}, \mathrm{F}_{[1,15]}=6.3 ; \mathrm{R}^{2}=0.25\right.$; $\mathrm{P}=0.024 ; \mathrm{K}, \mathrm{F}_{[1,15]}=11.5 ; \mathrm{R}^{2}=0.40 ; \mathrm{P}=0.004$; Table 2).

Table 2. The effect of broodstock holding environment on physical egg quality parameters and chorion element concentrations (means \pm std dev).

\begin{tabular}{lccc}
\hline Variable & Raceway & Tank & P-value \\
\hline Egg survival (\%) & $17.4 \pm 19.6$ & $58.6 \pm 10.6$ & $\mathrm{P}<0.001$ \\
Non-water hardened chorion breaking strength (N) & $0.7 \pm 0.3$ & $6.8 \pm 0.3$ & $\mathrm{P}<0.001$ \\
Water hardened chorion breaking strength (N) & $1.4 \pm 1.3$ & $20.1 \pm 1.0$ & $\mathrm{P}<0.001$ \\
Se chorion conc. (\%) & $2.6 \pm 1.8$ & $4.1 \pm 0.9$ & $\mathrm{P}=0.040$ \\
C chorion conc. (\%) & $48.8 \pm 1.8$ & $47.7 \pm 2.7$ & $\mathrm{P}=0.369$ \\
O chorion conc. (\%) & $38.4 \pm 2.5$ & $39.5 \pm 2.1$ & $\mathrm{P}=0.340$ \\
Na chorion conc. (\%) & $4.3 \pm 0.7$ & $4.5 \pm 0.8$ & $\mathrm{P}=0.677$ \\
Mg chorion conc. (\%) & $5.6 \pm 4.6$ & $3.7 \pm 0.7$ & $\mathrm{P}=0.213$ \\
P chorion conc. $(\%)$ & $5.1 \pm 1.7$ & $5.1 \pm 1.7$ & $\mathrm{P}=0.024$ \\
S chorion conc. $(\%)$ & $4.9 \pm 1.8$ & $4.1 \pm 1.6$ & $\mathrm{P}=0.347$ \\
Cl chorion conc. $(\%)$ & $3.4 \pm 1.1$ & $3.6 \pm 4.2$ & $\mathrm{P}=0.918$ \\
K chorion conc. $(\%)$ & $4.1 \pm 1.4$ & $2.2 \pm 1.0$ & $\mathrm{P}=0.004$ \\
Ca chorion conc. $(\%)$ & $3.7 \pm 1.5$ & $3.0 \pm 3.2$ & $\mathrm{P}=0.598$ \\
\hline
\end{tabular}




\section{Discussion}

The results show that $\mathrm{PC} 1$ scores explain $40 \%$ of variation in egg survival and thus provided a useful multivariate index of egg quality, combining a broad range of elements of egg quality to produce an index that increases with decreasing egg quality. The relationship between the PC1 scores and egg survival shows the benefits of using integrated methods of analysis where a number of independent variables can be combined into a single, usable measure of egg quality. The results indicate that brown trout reared in tank systems produced eggs of significantly higher quality compared to eggs produced by brown trout held in raceways. Previous studies have successfully used a similar approach to examine multiple complex determinants of welfare of salmonids (Turnbull et al., 2005; Adams et al., 2007).

However, other factors not measured during this experiment may also have had an effect. For example, Aegerter et al. (2005) reported differences in the presence of specific mRNA transcripts, between high and low quality eggs, while Arukwe and Goksoyr (2003) reported that low levels of yolk proteins stored within the egg prior to ovulation might affect embryogenesis and thus egg survival. Therefore, further studies integrating both chorion egg quality parameters and yolk egg quality parameters into a single measure of egg quality may explain more of the variation in egg survival than was shown within the current study.

Broodstock reared in tank and raceway systems produced eggs which differed in egg survival, chorion breaking strength (non water hardened and water hardened) and chorion Se concentrations. This strongly indicates that broodstock rearing environment modified these egg characteristics, thus eggs originating from trout reared in a tank system expressed higher egg survival, chorion breaking strength and chorion $\mathrm{Se}$ concentrations compared with eggs from trout held in the raceway.

The chorion breaking strength measurements for eggs obtained from fish held in the tank system were comparable to similar studies on other salmonids, however the measurements obtained for eggs produced by broodstock held in the raceway were distinctly lower (Zotin 1958; Iuchi et al., 1996). For example, eggs from rainbow trout ruptured under a force of $29 \mathrm{~N}, 24 \mathrm{~h}$ after being water hardened (Iuchi et al., 1996). This suggests that the females reared in the raceway system produced eggs with a reduced chorion breaking strength, rather than the tank system causing trout to produce eggs with increased chorion breaking strength.

The chorion is a proteinaceous membrane which surrounds the egg and protects the embryo inside from mechanical and chemical stressors during development (Kudo, 1992; Yamagami, 1992). Aquaculture procedures such as broodstock stripping and egg sorting can cause mechanical damage to the eggs due to the physical nature of the process, however, eggs with a more robust chorion are more likely to be able survive the stripping and sorting process intact and undamaged.
Fish reared in the tank system produced eggs with increased concentrations of chorionic Se, suggesting that eggs produced by broodstock held in the tank system were better protected from oxidative stress compared to eggs produced by raceway broodstock. Selenium plays a pivotal role against oxidative cellular injury (Rider et al., 2009). Of the 30 or so selenoproteins identified in mammals, a similar number of homologues have been recognised in fish (Kryukov and Gladyshev, 2000). The most studied of these are the enzymes glutathione peroxidase (GSH-Px), thioredoxin reductase (Trx-R), catalase, and superoxide dismutase. These are important molecules involved in intracellular antioxidant defence (Halliwell 1999; Arthur, 2000; Arteel and Sies, 2001). All broodstock diets contain some form of Se, which is usually stored and metabolised in the liver. This organ is also where the chorion proteins are manufactured before being transported to the ovary and overlaid onto the developing oocyte (Arukwe and Goksoyr, 2003; Rider et al., 2010).

Chorion concentrations of $\mathrm{P}$ and $\mathrm{K}$ were significantly higher in eggs produced by broodstock held in the raceway compared to the tank system. The elevated chorion concentrations of $\mathrm{P}$ and $\mathrm{K}$ may indicate poor egg development prior to and during ovulation. Craik and Harvey (1984) observed that protein linked phosphorus levels were higher during unsuccessful oocyte hydration compared to when oocytes successfully hydrated. Potassium ions are also essential during volume increase and water uptake of maturing oocytes although elevated levels of $\mathrm{K}$ are indicative of osmoregulatory failure in salmonids (Cardeilhac et al., 1979; Redding and Schreck, 1983; Bjornsson et al., 1989; Greeley et al., 1991; Liebert and Schreck, 2006). Phospholipids, inorganic phosphate and potassium are universally major components of living cells (Craik, 1982; Craik and Harvey, 1984, 1986; Lafleur and Thomas ,1991), however, in terms of their function within the chorion, this is most likely to be associated with egg hydration.

The most likely factor which may have affected the physiological status of the fish, and thus egg quality, was the hydrology within the holding systems. Although fish in both treatments experienced similar volumes of water passing through the tank, the way water entered the tanks and raceways was different. Water entering the tanks entered side on from three pipes, positioned equidistantly around the circular holding system, this resulted in the formation of a current, which the fish were regularly observed swimming against. Alternatively, water entering the raceway was supplied via an overhead pipe, which caused no such current to form. Previous studies have shown that increasing the current within a system causes fish to actively swim in order to maintain their position within the water column. Subsequently this has been shown to decrease physiological and behavioural stress responses in farmed fish by exercising fish and reducing attacks by conspecifics (Adams et al., 1995; Cutts et al., 1998; Damsgard and Arnesen, 1998). Stress is an energy demanding process and the fish have to mobilise 
energy substrates to metabolically cope with stress (Pottinger, 1998). It is possible that the current within the tanks may have allowed broodstock to devote more energy to reproduction and subsequently increased the quality of eggs produced.

In conclusion, results of both the integrated measures of chorion quality, individual chorion quality parameters, and egg survival rates suggest that the rearing environment had an effect on egg quality mediated through the broodstock. Eggs produced by brown trout reared in the tank system were of significantly higher quality compared to eggs produced by trout reared within the raceway. Welfare is an important aspect of aquaculture. However, information regarding the effect of holding environment on broodfish maturation and egg quality requires further research in order to understand the complex biological interactions.

\section{Acknowledgments}

This work was carried out thanks to funding from Alltech ${ }^{\circledR}$. We also thank Peter Hesketh and staff at Ae Fishery, Stuart Wilson, Rona Brennan, and David Fettes at S.C.E.N.E. for all their assistance.

\section{References}

Adams CE, Huntingford FA, Krpal J, Jobling M, Burnett SJ. 1995. Exercise, agonistic behaviour and food acquisition in Arctic charr, Salvelinus alpinus. Environ Biol Fish, 43:213-218.

Adams CE, Turnbull JF, Bell A, Bron JE, Huntingford FA. 2007. Multiple determinants of welfare in farmed fish: stocking density, disturbance, and aggression in Atlantic salmon (Salmo salar). Can $J$ Fish Aquat Sci, 64:336-344.

Aegerter S, Jalabert B, Bobe J. 2005. Large scale realtime PCR analysis of mRNA abundance in rainbow trout eggs in relationship with egg quality and postovulatory ageing. Mol Reprod Dev, 72:377-385.

Arteel GE, Sies H. 2001. The biochemistry of selenium and the glutathione system. Environ Toxicol Pharmacol, 10:153-158.

Arthur JR. 2000. The glutathione peroxidases. Cell Mol Life Sci, 57:1825-1835.

Arukwe A, Goksoyr A. 2003. Eggshell and egg yolk proteins in fish: hepatic proteins for the next generation: oogenetic, population, and evoluntionary implications of endocrine disruption. Comp Hepatol, 2:1-21.

Bjornsson BT, Young G, Lin RJ, Deftos LJ, Bern HA. 1989. Smoltification and seawater adaptation in Coho salmon (Oncorhynchus- kisutch) - plasma calcium regulation, osmoregulation, and calcitonin. Gen Comp Endocrinol, 74:346-354.

Bobe J, Labbe C, 2010. Egg and sperm quality in fish. Gen Comp Endocrinol, 165:535-548.

Bostock J, McAndrew B, Richards R, Jauncey K, Telfer T, Lorenzen K, Little D, Ross L, Handisyde N, Gatward I, Corner R. 2010. Aquaculture: global status and trends. Philos Trans R Soc B, 365:2897-2912.

Bromage N, Jones J, Randall C, Thrush M, Davies
B, Springate J, Duston J, Barker G. 1992. Broodstock management, fecundity, egg quality and the timing of egg production in the rainbow trout (Oncorhynchus mykiss). Aquaculture, 100:141-166.

Brooks S, Tyler CR, Sumpter JP. 1997. Quality in fish: what makes a good egg? Rev Fish Biol Fish, 7:387-416.

Campbell PM, Pottinger TG, Sumpter JP. 1992. Stress reduces the quality of gametes produced by rainbow trout. Biol Reprod, 47:1140-1150.

Cardeilhac PT, Simpson CF, Lovelock RL, Yosha SF, Calderwood HW, Gudat JC. 1979. Failure of osmoregulation with apparent potassium intoxication in marine teleosts - primary toxic effect of copper. Aquaculture, 17:231-239.

Craik JCA. 1982. Levels of phosphoprotein in the eggs and ovaries of some fish species. Comp Biochem Physiol B Biochem Mol Biol, 72:507-510.

Craik JCA, Harvey SM. 1984. Egg quality in rainbow trout - the relation between egg viability, selected aspects of egg composition, and time of stripping. Aquaculture, 40:115-134.

Craik JCA, Harvey SM. 1986. Phosphorus metabolism and water uptake during final maturation of ovaries of teleosts with pelagic and demersal eggs. Mar Biol, 90:285-289.

Cutts CJ, Metcalfe NB, Taylor AC. 1998. Aggression and growth depression in juvenile Atlantic salmon: consequence of individual variation in standard metabolic rate. J Fish Biol, 52:1026-1037.

Damsgard B, Arnesen AM. 1998. Feeding, growth and social interactions during smolting and seawater acclimation in Atlantic salmon, Salmo salar L. Aquaculture, 168:7-16.

Ebeling JM, Timmons MB. 2012. Recirculating Aquaculture Systems. In: (Tidwell JH (Ed.). Aquaculture Production Systems. Oxford, UK: WileyBlackwell.

Greeley MS, Hols H, Wallace RA. 1991. Changes in size, hydration and low-molecular weight osmotic effectors during meiotic maturation of Fundulus oocytes in-vivo. Comp Biochem Physiol A Physiol, 100:639-647.

Halliwell B. 1999. Establishing the significance and optimal intake of dietary antioxidants: the biomarker concept. Nutr Rev, 57:104-113.

Humane Killing of Animals under Schedule 1 to the Animals (Scientific Procedures) Act 1986: code of practice. 1997. London: The Stationery Office Books. $10 \mathrm{pp}$.

Iuchi I, Ha CR, Sugiyama H, Nomura K. 1996. Analysis of chorion hardening of eggs of rainbow trout, Oncorhynchus mykiss. Dev Growth Differ, 38:299-306.

Izquierdo MS, Fernandez-Palacios H, Tacon AGJ. 2001. Effect of broodstock nutrition on reproductive performance of fish. Aquaculture, 197:25-42.

Kinne O, Kinne EM. 1961. Rates of development in embryos of a cyprinodont fish exposed to different temperature-salinity-oxygen combinations. Can J Zool, 40:231-253.

Kjorsvik E, Mangorjensen A, Holmefjord I. 1990. Egg quality in fishes. Adv Mar Biol, 26:71-113.

Kryukov, GV, Gladyshev, VN. 2000. Selenium 
metabolism in zebrafish: multiplicity of selenoprotein genes and expression of a protein containing 17 selenocysteine residues. Genes Cells, 5:1049-1060.

Kudo S. 1992. Enzymatic basis for protection of fish embryos by the fertilization envelope. Experientia, 48:277-281.

Lafleur GJ, Thomas P. 1991. Evidence for a role of $\mathrm{Na}+, \mathrm{K}+-$ ATPase in the hydration of Atlantic croaker and spotted sea trout oocytes during final maturation. $J$ Exp Zool, 258:126-136.

Liebert AM, Schreck CB. 2006. Effects of acute stress on osmoregulation, feed intake, IGF-1, and cortisol in yearling steelhead trout (Oncorhynchus mykiss) during seawater adaptation. Gen Comp Endocrinol, 148:195202.

Mommens M, Fernandes JMO, Bizuayehu TT, Bolla SL, Johnston IA, Babiak I. 2011. Maternal gene expression in Atlantic halibut (Hippoglossushippoglossus L.) and its relation to egg quality. BMC Res Notes, 3:138. doi: 10.1186/1756-0500-3-138.

Norberg B, Valkner V, Huse J, Karlsen I, Grung GL. 1991. Ovulatory rhythms and egg viability in the Atlantic halibut (Hippoglossus- hippoglossus). Aquaculture, 97:365-371.

Oksanen L. 2001. Logic of experiments in ecology: is pseudoreplication a pseudoissue? Oikos, 94:27-38.

Oppen-Berntsen DO, Helvik JV, Walther BT. 1990. The major structural proteins of cod (Gadus morhua) egg shells and protein crosslinking during teleost egg hardening. Dev Biol, 137:258-265.

Pillay TVR. 1993. Aquaculture: Principles and Practices. Oxfoird, UK: Blackwell_Wiley. 575 pp.

Pottinger TG. 1998. Changes in blood cortisol, glucose and lactate in carp retained in anglers keep nets. $J$ Fish Biol, 53:728-742.
Redding JM, Schreck CB. 1983. Influence of ambient salinity on osmoregulation and cortisol concentration in yearling coho salmon during stress. Trans Am Fish Soc, 112:800-807.

Rider SA, Davies SJ, Jha AN, Fisher AA, Knight J, Sweetman JW. 2009. Supra-nutritional dietary intake of selenite and selenium yeast in normal and stressed rainbow trout (Oncorhynchus mykiss): implications on selenium status and health responses. Aquaculture, 295:282-291.

Rider SA, Davies SJ, Jha AN, Clough R, Sweetman JW. 2010. Bioavailability of co-supplemented organic and inorganic zinc and selenium sources in a white fishmeal-based rainbow trout (Oncorhynchus mykiss) diet. J Anim Physiol Anim Nutr, 94:99-110.

Ruddy PP, Potts WTW. 1969. Sodium balance in the eggs of Atlantic salmon (Salmo salar). J Exp Biol, 50:239-246.

Turnbull J, Bell A, Adams C, Bron J, Huntingford F. 2005. Stocking density and welfare of cage farmed Atlantic salmon: application of a multivariate analysis. Aquaculture, 243:121-132.

Washburn BS, Frye DJ, Hung SSO, Doroshov SI, Conte FS. 1990. Dietary effects on tissue composition, oogenesis and the reproductive performance of female rainbow trout (Oncorhynchus mykiss). Aquaculture, 90:179-195.

Yamagami K, Hamazaki TS, Yasumasu S, Masuda K, Iuchi I. 1992. Molecular and cellular basis of formation, hardening, and breakdown of the egg envelope in fish. Int Rev Cytol, 136:51-92.

Zotin AI. 1958. The Mechanism of hardening of the salmonid egg membrane after fertilization or spontaneous activation. $J$ Embryol Exp Morphol, 6:546568. 